\title{
BMJ Open Cost-effective analysis of teaching pelvic examination skills using Gynaecology Teaching Associates (GTAs) compared with manikin models (The CEAT Study)
}

Aisha Janjua, ${ }^{1}$ Tracy Roberts, ${ }^{2}$ Nicola Okeahialam, ${ }^{3}$ T Justin Clark $^{4}$

To cite: Janjua A, Roberts T, Okeahialam $\mathrm{N}$, et al. Costeffective analysis of teaching pelvic examination skills using Gynaecology Teaching Associates (GTAs) compared with manikin models (The CEAT Study). BMJ Open 2018;8:e015823. doi:10.1136/ bmjopen-2017-015823

- Prepublication history and additional material for this paper are available online. To view, please visit the journal (http:// dx.doi.org/10.1136/bmjopen2016-015823).

RCOG Annual Academic Meeting 2017(2 -3 March 2017)

Received 3 January 2017 Revised 6 June 2017 Accepted 4 August 2017

\section{Check for updates}

${ }^{1}$ Obstetrics and Gynaecology, Birmingham Heartlands Hospital Birmingham, UK

${ }^{2}$ Department of Health Economics Unit, School of Health and Population Science, The Public Health Building, University of Birmingham, Birmingham, UK

${ }^{3}$ Obstetrics and Gynaecology, London, UK

${ }^{4}$ Obstetrics and Gynaecology, Birmingham Women's Hospital, Birmingham, UK

Correspondence to

Dr Aisha Janjua;

aishajanjua@doctors.net.uk

\section{ABSTRACT}

Objective To determine the cost-effectiveness of Gynaecology Teaching Associate (GTA) teaching versus conventional pelvic model (manikin) teaching of pelvic examination skills for final year medical students within a UK undergraduate obstetrics and gynaecology (O\&G) curriculum.

Methods An economic evaluation was carried out alongside a randomised controlled trial involving 492 final year medical students. 240 students received manikin teaching, and 241 GTA-led teaching. 418 (85\%) students completed their assessment. Proficiency in gynaecological pelvic examination on GTAs was estimated by a senior clinical examiner, blinded to the method of teaching, using a standardised assessment tool. University of Birmingham Medical School thresholds were applied to determine proficiency levels; competence (pass) 50\%, merit 60\% and distinction $70 \%$. Costs incurred in the delivery of both the educational pathways (control and intervention) were combined. All costs are reported in 2013-2014 prices and earlier costs adjusted using inflation indices.

Outcome measures Cost per student competent in pelvic examination at completion of a 5-week clinical $0 \& G$ placement.

Results GTA teaching was more effective compared with conventional teaching with 12 more students considered competent at pass level and 28 more students competent at merit and distinction levels, respectively. However, the average cost of GTA teaching was $£ 45.06$ per student compared with $£ 7.40$ per student for conventional teaching, with an increased cost of $£ 37.66$ per student. The incremental cost-effectiveness ratio demonstrated that it cost an additional $£ 640.20$ per competent student and $£ 274.37$ per student competent at merit level and $£ 274.37$ at distinction level compared with conventional manikin-based teaching.

Conclusions GTA teaching of female pelvic examination at the start of undergraduate medical student $0 \& \mathrm{G}$ clinical placements is shown to cost more and be more effective. GTA teaching is likely to be considered cost-effective in the context of other tests, and over the lifespan of a competent doctor's career.

Trial registration number NCT01944592.
Strengths and limitations of this study

- The RCT represents the largest randomised prospective study to estimate the costs and effectiveness of Gynaecology Teaching Associates (GTAs) compared with traditional manikin-based teaching of female pelvic examination to medical students.

- Our assessment of costs in both the GTA and manikin groups of the trial was based on real, direct salary expense.

- We conducted sensitivity analyses which demonstrated the stability of our base case findings and enhanced their generalisability.

- Economic data were collected retrospectively in contrast to the prospectively collected clinical outcome data. However, extensive sensitivity analyses around plausible ranges of costs did not substantially change our main findings.

- The ideal length of follow-up required to answer economic questions is longer than follow-up necessary to answer clinical applications. The economic analysis reflects short-term outcomes, that is, competence at the end of the placement. Long-term outcomes such as proficiency as a qualified junior doctor, patient safety, costs of unnecessary investigations ordered and patient satisfaction were not feasible within this study.

\section{INTRODUCTION}

Female pelvic examination teaching poses practical challenges for medical students. The intimate nature of the examination, time pressures faced in the clinical environment and patient expectations ${ }^{1}$ contribute towards the possibility that medical students in the UK can graduate without ever performing a vaginal examination on a conscious patient. ${ }^{2} 3$ Current teaching methods focus on theoretical knowledge of pelvic anatomy, communication skills role played with a teacher, practice of skills on an anatomical model (manikin) and 
supervised teaching in outpatient clinics and theatres. However, these current teaching approaches do not allow the nuances of this intimate examination to be appreciated and may not be the most efficient way of ensuring medical students attain a level of proficiency required by the General Medical Council (GMC). ${ }^{4}$ One potential solution is the introduction of expert patients known as Gynaecology Teaching Associates (GTAs), who are recruited and trained to instruct medical students in achieving practical experience. ${ }^{56}$

Despite apparent educational benefits of GTA-led teaching, ${ }^{7}$ this educational innovation is an expensive human resource. ${ }^{8-11}$ Those tasked with designing and delivering undergraduate medical education need to do so within the context of financial constraints on higher education and mindful of other competing priority areas within medical school curricula. Thus, in the climate of existing educational and National Health Service (NHS) financial restraints, new educational interventions need to be effective and cost-effective in delivering learning outcomes in key components of the curriculum. There are also few economic assessments evaluating the use of expert patients in teaching non-genital tract examinations ${ }^{12}{ }^{13}$ and no rigorous, formal economic analyses of GTA teaching of gynaecological examination. Thus, in light of this uncertainty we undertook an economic evaluation alongside a large RCT to estimate the cost-effectiveness of a GTA-led teaching programme for pelvic examination skills in comparison with the use of traditional pelvic model (manikin) teaching.

\section{METHODS}

This economic evaluation was carried out alongside the Teaching associates Randomised to evaluate the effectiveness of Gynaecological pelvic Examination versus
Traditional teaching using manikins (TARGET) trial; a pragmatic single-centre single-blinded randomised controlled trial (RCT) comparing pelvic examination teaching using anatomic models, that is, pelvic manikins (control) with expert patients-GTAssee online supplementary appendix 1 . Recruitment to the TARGET RCT took place from 27 August 2013 to 12 December 2014.

Teaching took place during the first of 5 weeks of the students' placements in obstetrics and gynaecology (O\&G), prior to graduation. The trial outcome measures were confidence and competence in performing pelvic examinations assessed at the end of the fifth week of the student's placements. Preteaching and pre-assessment questionnaires were distributed that included the students' own perceptions of their confidence and competence levels. Scoring by assessors was conducted using a $0-10 \mathrm{~cm}$ Visual Analogue Scale (VAS) on a bespoke assessment tool. The assessors marking their examination were blinded to the intervention the students had received. The data from the RCT have been extrapolated to explore which of the two teaching methods was more cost-effective in terms of the outcome of competence as determined by the assessors.

Figure 1 shows the composition and course of the control (manikin) and experimental (GTA) teaching interventions during the RCT. The introductory PowerPoint presentations were the same for each teaching intervention. The 2-hour teaching sessions took place between 17:00 and 19:00 hours. After the initial teaching, the participants completed their 5-week O\&G placements at their assigned hospitals within the West Midlands, all of which were affiliated to the University of Birmingham Medical School. Opportunities during the clinical placement for conducting supervised pelvic
Manikin Teaching

- Powerpoint Presentation by Lecturer in Gynaecology - 10 mins

- Communication Skills discussion by Lecturer including consent, preparation for exam

- 10 mins

- Lecturer examines manikin, observed by all students (discusses abdominal examination as no abdomen on the pelvic model)

- 10 mins

- Each student examines the manikin once, with ongoing feedback - 40 mins

- Each student examines the manikin again, with feedback at the end - 40 mins

- Debrief and feedback to each student after their examination - 10 mins
GTA Teaching

- Powerpoint Presentation by GTA

- 10 mins

- Communication Skills Role Play between GTAs including consent, preparation for exam

- 10 mins

- GTA 1 examines GTA 2, observed by all students

- 10 mins

- Each student performes full gynaecological examination on GTA 1 once, with ongoing feedback

- 40 mins

- Each student performes full gynaecological examination on GTA 2 once, with feedback at the end

40 mins

- Debrief and feedback to each student after their examination

- 10 mins

Figure 1 Programme of teaching (manikin and GTA). GTA, Gynaecology Teaching Associate. 
examination either in O\&G outpatient department settings or operating theatres were available regardless of initial teaching allocation.

\section{RESOURCE AND COST DEFINITION}

All costs in the analysis are in UK pounds (£), based on 2013/2014 values. Apart from the intervention, all other resource use is the same for all students in control and intervention arm, respectively. The costs have been calculated as a bottom-up approach incorporating all resources used for the purposes of teaching in the manikin and GTA arm. The Birmingham Women's Hospital (BWH) finance department provided the costs of running the Gynaecology Outpatient Department (GOPD), including indirect facilities, facilities, depreciation, divided and overhead costs of $10 \%$ factored in.

\section{Manikin-based teaching}

A clinical teaching fellow (CTF) was employed by BWH to teach final year medical students during their O\&G placement. The cost to the hospital of employing the CTF was $£ 43434$ per annum over 52 weeks. This base salary reflects no on-calls, and an average working week of 40 hours. Therefore, the hourly cost is calculated at $£ 20.82$. Actual costs of the faculty member teaching manikin examination may vary as there is a pay scale depending on the number of years worked in the NHS, prior to taking the CTF post. No travel costs are accounted for as the CTF is on site at BWH and continued to teach the sessions after working hours.

The total invoice to $\mathrm{BWH}$ of manikin purchase was $£ 3301.75$. However, for the purposes of the trial, costs of delivery have been excluded. During the trial, the pelvic manikin was used from 27 August 2013 to 14 November 2014, where teaching was only conducted during the first week of the O\&G placement. Costs were calculated per week of use and are appropriately annuitised following the methods by Drummond et al ${ }^{14}$ (see online supplementary appendix 2).

\section{GTA-based teaching}

The resources and costs associated with GTA teaching are shown in table 1. Each GTA was paid £30 per hour, which included compensation for travel expenses.

\section{OUTCOMES}

Assessment of competence took place at the end of the 5-week placement in O\&G. This comprised a clinical scenario requiring the student to explain and conduct a speculum and bimanual examination of a female patient attending an outpatient clinic. The role of the patient was played by one of the GTA faculty and students were observed by a single passive examiner who was blinded to the teaching the student had received. Examiners completed a bespoke pelvic assessment tool evaluating seven domains considered important in gynaecological

\begin{tabular}{|c|c|c|}
\hline Resource & Details & Cost (£) \\
\hline \multicolumn{3}{|l|}{ Manikin arm costs } \\
\hline $\begin{array}{l}\text { Lecturer/specialist } \\
\text { registrar }\end{array}$ & & $£ 20.82$ per hour \\
\hline Manikin * & Costs per week & $\begin{array}{l}£ 14.50 \text { per } \\
\text { teaching week }\end{array}$ \\
\hline $\begin{array}{l}\text { Disposable } \\
\text { speculum † }\end{array}$ & $\begin{array}{l}\text { One speculum } \\
\text { required for the } \\
\text { teaching session }\end{array}$ & $\begin{array}{l}£ 0.77 \text { per } \\
\text { speculum }\end{array}$ \\
\hline \multicolumn{3}{|l|}{ GTA arm costs } \\
\hline GTA pay & & $£ 30$ per hour \\
\hline $\begin{array}{l}\text { Disposable } \\
\text { speculum † }\end{array}$ & $\begin{array}{l}\text { Two speculums used } \\
\text { per student }\end{array}$ & $\begin{array}{l}£ 0.77 \text { per } \\
\text { speculum }\end{array}$ \\
\hline Aquagel $\ddagger$ & $\begin{array}{l}\text { Two sachets } \\
\text { required per student }\end{array}$ & $£ 1.54$ per student \\
\hline \multirow[t]{2}{*}{ Gloves § } & $\begin{array}{l}\text { Four gloves per } \\
\text { student }\end{array}$ & $£ 0.10$ per student \\
\hline & $\begin{array}{l}\text { Two gloves for the } \\
\text { GTA demonstration }\end{array}$ & $£ 0.05$ per GTA \\
\hline $\begin{array}{l}\text { Couch roll } \\
\text { (tissue)ף }\end{array}$ & & $£ 2.76$ per week \\
\hline Tissue box ** & & $£ 7.20$ per week \\
\hline
\end{tabular}

*See online supplementary appendix 2.

†Twenty-five speculums priced at $£ 19.23$ including VAT.

$\ddagger 5 \mathrm{~g}$ package priced at $£ 73.80$ for 48 sachets. One sachet is adequate for one full examination including application on the speculum for insertion and on the gloved fingers for bimanual examination.

$\S £ 5$ per box of 200 disposable latex-free gloves. A pair of gloves is required per examination, and two examinations performed within one GTA session, the total cost of four gloves was $£ 0.10$ per student. For the initial GTA demonstration of examination, £0.05 has been calculated.

१TTwo hundred sheets priced at $£ 5.51$.

**Hundred tissues priced at $£ 3.60$.

examination. The students' assessments were performed on a $0-10 \mathrm{~cm}$ VAS scale over seven domains including 'Global Assessment'. The scores in the seven different domains were then averaged to provide a final value or 'score' for that student which has been used as the educational outcome in this economic evaluation.

In the absence of a validated defined numerical threshold of competence, the University of Birmingham Medical School recommended marking thresholds were applied; a pass score should be $50 \%$ (corresponding to an average VAS score $\geq 5.0$ ), a merit $60 \%$ (average VAS score $\geq 6.0$ ) and distinction $70 \%$ (average VAS score $\geq 7.0$ ) (see online supplementary appendix 3). We calculated cost per competence level achieved using each of the aforementioned levels as the threshold.

The cost per competent student was obtained from a single study-based estimate with a sufficient source of clinical effectiveness data due to large number of participants ( 400 students). The single-blinded RCT had equal numbers of participants in the control and 
intervention arm, thus making it a useful means of comparison for cost-effectiveness.

\section{ASSUMPTIONS}

The cost of recruiting and employing the GTAs included flyer advertisements on boards around BWH and the University of Birmingham Hospital and use of hospital email. These associated costs were considered negligible. The initial meeting costs included the 'Seminar Room' hire and Consultant time, which in this case was performed out of working hours. Rooms within the Education Resource Centre at the BWH are chargeable between 09:00 and 17:00 hours. No costs were incurred for the first meetings with potential GTAs who were keen on finding out what pelvic examination skill training of undergraduate teaching of medical students would involve. Two further teaching sessions took place in the GOPD, where one specialist registrar and the CTF taught the GTAs the knowledge, skill and communication skills required to perform a full pelvic examination. The costs of training have been assumed as neutral rather than incorporated into the cost-effectiveness analysis. Each medical school, hospital or institution would face similar start-up costs depending on local teaching facilities and staff present.

The study assumed that the aforementioned equipment including number of gloves and speculums are accurate. It was assumed that all equipment during the teaching session functioned correctly and no additional costs have been assumed to account for extra equipment requirements over and above those already estimated. The presence of functioning pelvic models (manikins) was assumed in all hospitals and the estimated 5-year lifespan of the pelvic models has been factored into the analysis. The costs reported are the actual costs incurred, and could reflect the minimum costs, with actual costs and cost differentials being potentially higher.

\section{ANALYSIS}

In the first stage of the analysis, we conducted a cost consequence analysis that involved comparing the costs and outcomes (competency in pelvic examination expressed as achieving a threshold score of $50 \%$ or more on an objective structured clinical examination (OSCE)) associated with the control and intervention arm of the RCT in a disaggregated manner. ${ }^{14}$ The purpose of this first analysis is to explore whether one teaching method dominated the other (ie, more effective and less costly or the converse). In the absence of a dominating teaching method, an additional cost-effectiveness analysis was planned with the results expressed in terms of the additional cost per additionally competent medical student at the end of a 5-week clinical placement in $\mathrm{O} \& \mathrm{G}$.

Both a probabilistic sensitivity analysis (PSA) and a series of one-way deterministic sensitivity (DSA) analysis were carried out to explore the robustness of the base case results to plausible variations in teaching methods and facilities used. In the base case analysis, costs were compared in the two teaching arms of the RCT (control vs intervention) excluding room hire, that is, tutorial room, GOPD examination room and clinical skills room (see online supplementary appendix 4). The costs of individual items such as gloves, Aquagel, couch roll and tissue boxes were identified. In the deterministic analysis, uncertainties around the key costs in the base case analysis were performed and in the PSA a cost-effectiveness analysis curve (CEAC) was generated.

Model-based analysis (PSA) is required to explore all uncertainties together and to provide a distribution in the cost-effectiveness plane. One-dimensional bootstrapping is used to find a CI around a single variable such as a cost. Two-dimensional bootstrapping, in which costs and outcomes for the same medical student are resampled together, is the appropriate method to generate a distribution in the cost-effectiveness plane. It is therefore the equivalent of a PSA for a model.

\section{Sensitivity analyses}

Sensitivity analyses included: (i) the costs of tutorial and clinical skills room hire in accordance with the Education Resource Centre rental policy. The BWH costs come from the finance department provided the costs of running the GOPD, including indirect facilities, facilities, depreciation, divided and overhead costs of $10 \%$ factored in. For the manikin arm, the Clinical Skills Room in the ERC at BWH was used for both the initial PowerPoint teaching and examination of the manikin. The cost per working day (8hours) was £200. Therefore, the cost for the 2 hours of teaching required was £50. For the GTA arm, a tutorial and GOPD room were both used for teaching purposes. A tutorial room in the ERC was used for the initial PowerPoint teaching for the medical students, which lasted $10 \mathrm{~min}$. The cost per working day (8hours) was $£ 100$. Therefore, the cost for the 10 min of teaching was £2.08. The cost per 40 hour week for use of the $7.9 \mathrm{~m}^{2}$ examination room use were calculated from costs incurred to the $\mathrm{BWH}$ and provided by its finance department. These were estimated to be $£ 333$ per week such that 1 hour of use would cost $£ 8.33$ (table 2). (ii) Changing the interest rate on the annual cost of capital outlay from $3 \%$ to $1.5 \%$. Drummond $e^{2} \mathrm{al}^{14}$ suggested an interest rate on the annual cost of capital outlay between $1.5 \%$ and $3 \%$. The base case analysis was calculated with $3 \%$, with the sensitivity analysis changing this to $1.5 \%$. (iii) Ideal costs

Table 2 Gynaecological outpatient room hire cost (Birmingham Women's Hospital, UK)

$£$ Including overhead

Average cost $(10 \%)$

Cost per week (40-hour week, 333

ie, 5 days $\times 8$ hours' work)

Cost per month 2665 
of GTAs for teaching, that is, GTAs paid for a maximum of 2 hours for teaching eight students, rather than extended hour costs claimed during the trial. During the research study, it was recommended that GTA teaching time was limited to 2 hours, although some flexibility in the study was allowed due to the learning effect. In the event of request and demand on GTAs, the time slots extended beyond that time frame and a longer teaching session occurred in some circumstances, for example, $90 \mathrm{~min}$. While it might have been necessary for some students to require a longer period of teaching, the necessity of it being longer was not very clear. This sensitivity analysis was conducted assuming the same effectiveness of GTAs with time limited to the recommended 2 hours. Over time the experience of using the GTAs would become refined and streamlined. They may not require $90 \mathrm{~min}$, and may be able to achieve all their educational objectives easily within the 2 hours. (iv) Reducing GTA cost to $£ 20$ per hour. The only other provision of GTAs is in London where 'Community Health South London NHS Trust employed successful candidates and paid them £20/ hour'. ${ }^{8}$ However, cost-effectiveness has never been evaluated prior to this study. The change in pay from $£ 30 /$ hour, which is the fees incurred in the RCT, to £20/hour was to reflect this option. (v) Including GTA training cost. A faculty of eight GTAs were recruited by poster advertisements followed by formal interviews. Suitable applicants were selected and then taught how to demonstrate and teach clinical skills by a lecturer in O\&G over a 3-month period with six sessions in total lasting 2 hours each. The GTAs then conducted six teaching sessions under the direct supervision of the lecturer, with each session lasting 2 hours.

\section{RESULTS}

\section{Competence levels}

Of the 492 students randomised into the TARGET trial, 408 (83\%) completed their competency assessment at students at the end of their 5-week clinical O\&G placement; 310/408 achieved pass-level competency (50\% overall score), 240 merit-level scores and 182 distinction-level assessment scores. Table 3 shows student competency according to group allocation and stratified by predefined competency thresholds.

\section{Base case analysis}

The results for the base case analysis are presented in table 4 . A full breakdown of costs is provided in online supplementary appendix 4 . The overall costs of the GTA and manikin teaching arms were $£ 1509.21$ and $£ 9191.60$, respectively. The number of students found to be competent at $50 \%$, $60 \%$ and $70 \%$ were greater in the GTA arm compared with the manikin arm (table 3 ). Therefore, the difference in competence at each of these levels was 12, 28 and 28 students, respectively.

The incremental cost-effectiveness ratios (ICERs) demonstrated that it costs an additional $£ 640.20$ per competent student and $£ 274.37$ per student competent at merit level and $£ 274.37$ at distinction level compared with conventional manikin-based teaching (table 4).

\section{Deterministic sensitivity analysis and probabilistic sensitivity analysis}

Holding the outcome data constant, one-way deterministic sensitivity analyses presents the overall difference in costs when additional costs were added. As shown in

Table 3 Competence levels (University of Birmingham regulations - see online supplementary appendix 3)

\begin{tabular}{lllll}
$\begin{array}{l}\text { Competence } \\
\text { level }\end{array}$ & $\begin{array}{l}\text { Total number of } \\
\text { students }\end{array}$ & $\begin{array}{l}\text { Students taught by GTA } \\
\text { (intervention) }\end{array}$ & $\begin{array}{l}\text { Students taught on a } \\
\text { manikin } \\
\text { (control) }\end{array}$ & $\begin{array}{l}\text { Additional competence of } \\
\text { GTA compared with manikin }\end{array}$ \\
\hline$<50 \%$ & 95 & 43 & 52 & -9 \\
$\geq 50 \%$ & 310 & 161 & 149 & +12 \\
$\geq 60 \%$ & 240 & 134 & 106 & +28 \\
$\geq 70 \%$ & 182 & 105 & 77 & +28 \\
\hline
\end{tabular}

GTA, Gynaecology Teaching Associate.

Table 4 Cost-effectiveness results (base case)

\begin{tabular}{llll}
\hline & $\begin{array}{l}\text { GTA } \\
\mathbf{n = 2 0 4}\end{array}$ & $\begin{array}{l}\text { Manikin } \\
\mathbf{n = 2 0 4}\end{array}$ & Mean difference \\
\hline Overall costs $(£)$ & 9191.60 & 1509.21 & 7682.39 \\
Costs per students in the trial arm $(£)$ & 45.06 & 7.40 & 37.66 \\
ICER for GTA compared with manikin & & & \\
ICER 50\% competence $(\Delta \operatorname{cost} / \Delta$ competence difference) & 640.20 & & \\
ICER 60\% competence $(\triangle \operatorname{cost} / \Delta$ competence) & 274.37 & & \\
ICER 70\% competence $(\triangle \operatorname{cost} / \triangle$ competence) & 274.37 & \\
\hline
\end{tabular}

GTA, Gynaecology Teaching Associate; ICER, incrementalcost-effectivenessratio. 
Table 5 Costs-effectiveness results (DSA)

\begin{tabular}{llllll}
\hline & $\begin{array}{l}\text { DSA 2 (interest } \\
\text { DSA 1 (inclusion } \\
\text { of room hire) }\end{array}$ & $\begin{array}{l}\text { DSA 3 (ideal } \\
\text { rate change to } \\
\mathbf{1 . 5 \%}\end{array}$ & $\begin{array}{l}\text { DSA 4 } \\
\text { costs of GTA } \\
\text { teaching) }\end{array}$ & $\begin{array}{l}\text { DSA 5 (GTA } \\
\text { (reduce GTA cost } \\
\text { to per hour) }\end{array}$ & $\begin{array}{l}\text { training cost } \\
\text { included) }\end{array}$ \\
\hline $\begin{array}{l}\text { Additional cost of GTA compared } \\
\text { with manikin }\end{array}$ & 7075.10 & 7686.88 & 8317.39 & 5485.39 \\
$\begin{array}{l}\text { Cost difference per student in } \\
\text { RCT arm (n=204) }\end{array}$ & 34.68 & 37.68 & 40.77 & 26.89 \\
\hline $\begin{array}{l}\text { ICER 50\% competence } \\
\text { ICER 60\% competence }\end{array}$ & 589.59 & 640.57 & 693.12 & 457.12 & 44.94 \\
\hline ICER 70\% competence & 252.68 & 274.53 & 297.05 & 195.91 & 764.06 \\
\hline
\end{tabular}

DSA, deterministic sensitivity analysis; GTA, Gynaecology Teaching Associate; ICER, incrementalcost-effectivenessratio; RCT, randomised controlled trial.

table 5, GTA teaching remained more expensive but more effective in all the scenarios considered. A full breakdown of costs is provided in online supplementary appendix 5.

The results of the PSA are presented in figure 2. The CEACs (figure 2) demonstrate that there is an increased probability of cost-effectiveness with using GTAs to train students to a $60 \%$ or $70 \%$ competence level, as compared with a $50 \%$ competence level.

\section{DISCUSSION}

\section{Statement of principal findings}

The use of GTAs is cost-effective for training undergraduate medical students in becoming proficient in gynaecological pelvic examination beyond basic university competency expectations. The additional £274.37 investment from medical schools to train a student towards 'merit' or 'distinction' level competency appears viable.
The economic advantage of GTA teaching of final year medical students for achieving $50 \%$ 'pass' level competency was less pronounced with nearly one in four students failing to achieve the minimum threshold in both trial groups. A higher financial outlay of $£ 640.20$ in the GTA group to gain an additionally competent student is again within feasible limits, but there is greater uncertainty around the cost-effectiveness of the GTA intervention even at higher willingness-to-pay thresholds. This finding may be explained by the fact that low-fidelity manikin-based teaching appears to be adequate in training students to reach the minimum basic competency threshold, but the limitations of training on an inanimate anatomic pelvic model precludes higher technical skills, including abilities in communication, to be acquired. Thus, it appears that we can be more confident in the fiscal argument to support GTA teaching

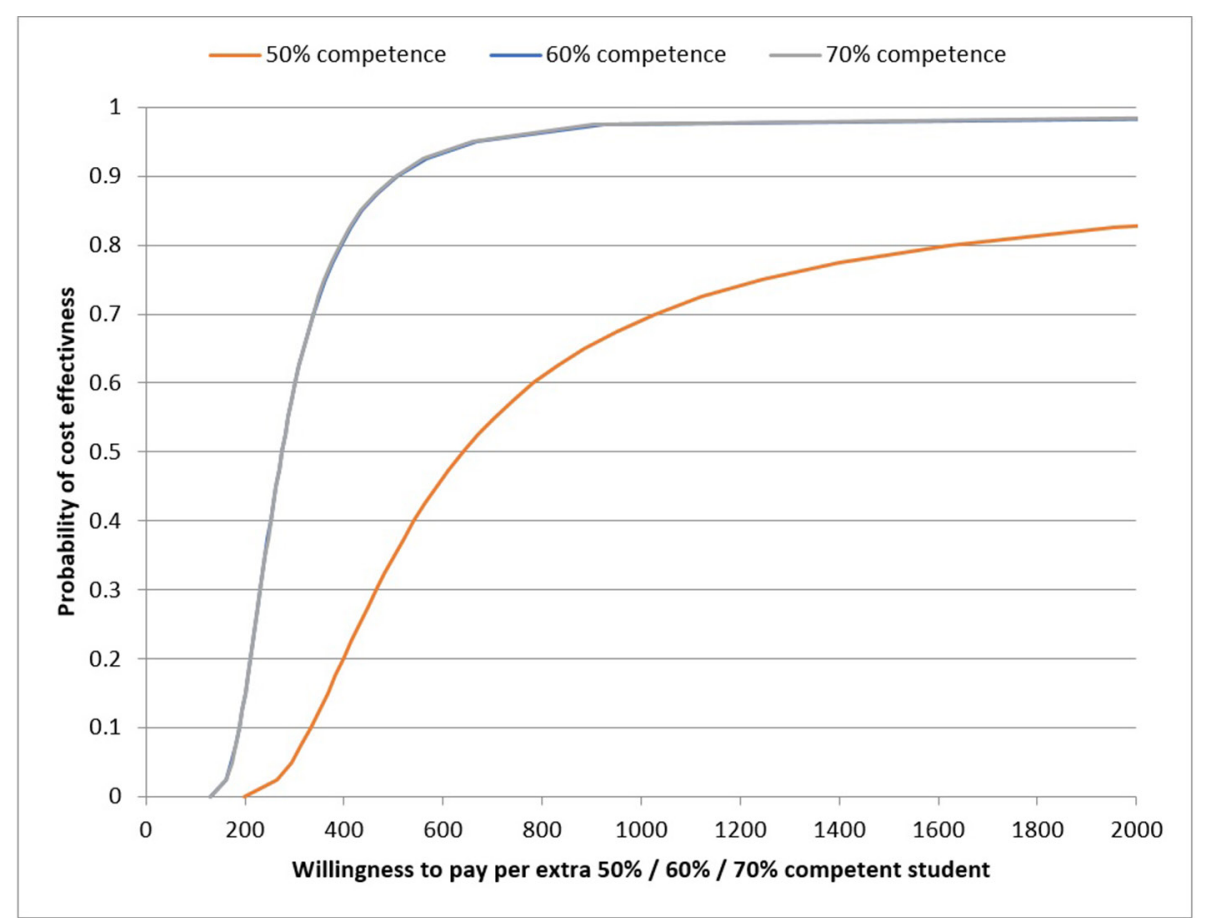

Figure 2 Cost-effectiveness acceptability curves for $50 \%, 60 \%$ and $70 \%$ competence. 
programmes to achieve higher level competency in female pelvic examination as opposed to simply attaining basic aptitude. These inferences are further supported by the minimal change in results observed in sensitivity analyses.

Our base case analysis is reflective of the real world where gynaecological outpatient examination rooms are already in existence. GTA teaching takes place after hours in most cases because the GTAs themselves mostly have work commitments and can only be available for teaching after outpatient clinic hours. In this situation, there is unlikely to be any conflict between GTA teaching and clinical demands for the examination rooms in a general gynaecological outpatient department.

\section{Strengths and limitations of this study}

This economic analysis was conducted alongside a highquality RCT, the TARGET trial which represents the largest randomised prospective study to estimate the costs and effectiveness of GTAs compared with traditional manikin-based teaching of female pelvic examination to medical students. The trial had good follow-up and completeness of clinical outcome data. Our assessment of costs in both the GTA and manikin groups of the trial were based on real, direct salary expense; we had invoices of all expenses incurred with the GTAs, and we accounted for all likely expenses that could be incurred with both arms of the trial, for example, speculums, gloves, couch roll, tissue box, etc. Furthermore, we conducted sensitivity analyses which demonstrated the stability of our base case findings and enhance their generalisability. Thus, these methodological strengths support the validity of our results. We conducted several sensitivity analyses and a PSA to explore the impact of changing the costs on the results. Given the limitations of the cost data and the precision of the clinical outcome data, more extensive statistical analyses would be unlikely to affect the level of confidence in our findings.

Limitations of our approach include the fact that the robustness of collected economic data may be less compared with clinical data because the former were collected retrospectively in contrast to the prospectively collected clinical outcome data. Thus, there may be greater inaccuracy around estimation of the costs as opposed to the educational outcomes. However, extensive sensitivity analyses around plausible ranges of costs did not substantially change our main findings. Randomisation in the TARGET trial was stratified by gender but in the interests of simplicity and clarity, the economic analysis did not explore the differences in costs and outcomes in subgroups of students (eg, age, prior experience, ethnicity, cultural beliefs, etc). GTA training is likely to be a formal recruitment process and although not initially included in the base case analysis, it has been considered in the sensitivity analysis. If the GTAs are employed for an extended period, the training costs are likely to become insignificant over time. Although every educational institute would incur this start-up cost, it is one that is variable and depends on the ability to keep the same GTAs in the faculty.

The ideal length of follow-up required to answer economic questions is longer than follow-up necessary to answer clinical applications. The economic analysis reflects short-term outcomes, that is, competence at the end of the placement. Long-term outcomes such as proficiency as a qualified junior doctor, patient safety, costs of unnecessary investigations ordered and patient satisfaction were not feasible within this study. We also did not evaluate the cost-effectiveness of the GTA intervention from a student or patient perspective such that confidence, calmness and other important qualitative outcomes were not accounted for.

\section{Comparison with other studies}

One of the main obstacles to the introduction of high-fidelity simulation including use of expert patients is their additional costs. Thus, formal economic evaluations such as the current one presented are needed to justify any additional investment if a demonstrable educational benefit can be observed. Thus, it is surprising that we could not identify any other formal economic studies. Most controlled studies evaluating GTAs are observational and there is considerable heterogeneity between the design of studies including the way in which GTAs were used, the type of students, comparators and timing of assessments. ${ }^{7}$ This observed variation limits the generalisability of findings and this is true for economic assessments where the costs of educational programmes, salaries, etc inevitably will vary both within and across national borders. Thus, precise economic comparisons are difficult to make.

Aamodt $e t a l^{13}$ used generic physical exam teaching associates (PETAs) for teaching a variety of physical examination skills but the organ systems evaluated were not specified so we cannot easily compare with our current study evaluating intimate female examination. The authors found salary cost savings because PETAs were used to replace the higher expense of using a faculty of clinicians. Another US study by Allen $e t \mathrm{al}^{15}$ also evaluated the use of patient educators to train students in 'head to toe' examination skills and while they found mean student performance was statistically lower with compared with clinician-led instruction this was marginal (two percentage points on average) and significant educator salary costs per student declined from US\$449 in 2006 to US\$196 in 2008. Black and Marcoux ${ }^{12}$ and Hasle et $a l^{16}$ also employed simulated patients across a variety of examination systems and found salary cost-savings without apparent compromise in student performance. Thus, these studies appear to also support the use of trained lay educators physical exam instruction from a financial view point because educational outcomes are similar but they are a less costly resource. However, in the absence of a formal economic assessment such as ours and the use of a robust educational outcome measure, the inferences we can derive are weak especially when trying to extrapolate to intimate female examination. 


\section{Meaning of the study—implication for clinicians/policy} makers

The $\mathrm{GMC}^{4}$ and most academic leads believe that competency in gynaecological examination is a core clinical requirement for graduating doctors (personal communication Janjua A, 2016). Thus, the use of GTAs may provide a financially sound, effective solution especially in an area where it is increasingly difficult for students to gain experience given the intimacy of the examination, pressures on supervising clinicians' time and patients' expectations. ${ }^{1} 17$ This contention is further supported when one considers the potential patient resource and safety implications of inadequately trained junior doctors, especially in acute medical situations. ${ }^{15}$ If an examination is performed competently, further unnecessary investigations and interventions can be avoided. However, the study is only limited to existing costs of teaching, and the ramifications as well as future costs of the lack of excellent teaching need to be explored further.

Decision makers such as the National Institute for Health and Care Excellence compared the results of economic evaluations to a predefined acceptable threshold in terms of cost per quality-adjusted life-year (QALY), but since the results of cost-effectiveness analysis presented here are in natural units and not QALYS there is no predefined threshold with which to compare the results of this study which makes interpretation difficult. Furthermore, cost-effectiveness thresholds have been arbitrarily set and accepted for clinical interventions. ${ }^{18}$ In contrast, there is no minimum acceptable ICER for educational outcomes and those policy makers within universities tasked with teaching medical students according to GMC minimum requirements need to take a view as to the benefit of employing expert patients such as GTAs. Moreover, our economic analysis fully supports the use of GTAs for training more students to become exceptional in pelvic examination but not necessarily for acquiring mediocrity. Thus, educationalists and those setting medical school curricula need to decide whether they consider GTAs to be cost-effective across all competency thresholds or for achieving higher level competencies beyond minimal GMC requirements. When considering these caveats, policy makers should be cognisant of the fact that the O\&G clinical placement is generally the only opportunity for medical students to gain experience in female pelvic examinations during their undergraduate years before independent practising as a junior doctor.

\section{Unanswered questions and future research}

Our trial, as with most GTA programmes in the UK universities (personal communication, Janjua A, 2016) used them for a single session early in students' clinical placement. However, a greater exploration as to the repeated use of GTAs throughout the clinical placements may change the cost-effectiveness in either direction. Furthermore, to investigate the true cost-effectiveness of GTA teaching, we need to look beyond just the outcome of short-term student competence outside of the clinical environment, and look at long-term healthcare and cost outcomes with regard to impact on patient safety.

It is likely that a multifaceted approach is desirable to help medical students achieve competency in gynaecological pelvic examination. This may use low-fidelity simulation with manikins, computer simulations, expert patients and supervision in the clinical setting. Packages of training should be evaluated for cost-effectiveness and with technological advances in simulation this may incorporate assessment of high-fidelity simulation manikins designed to provide greater realism.

\section{CONCLUSION}

Pelvic examination in gynaecology is an important core skill for medical students to become competent in prior to graduation. They will inevitably require this skill as junior doctors in acute settings such as accident and emergency departments and O\&G wards as well as electively in many medical disciplines involving the care of women but especially in general practice and O\&G. Our cost-effectiveness analysis, comparing traditional teaching method on a manikin with GTA-led teaching of pelvic examination skills for final year medical students within the O\&G curriculum, conducted alongside a large RCT supported the economic case for the use of GTAs to help medical students acquire competency in this core skill, and more compellingly for achieving higher levels of proficiency. Further research is needed to replicate our findings in other educational settings, to compare GTAs against other multifaceted packages of training, and to explore long-term clinical outcomes as well as to evaluate the impact of GTA training on student and patient acceptability and experience.

Acknowledgements The authors would like to thank all the GTAs involved in the trial, and Ms Sheila Bascoe, Undergraduate Coordinator at Birmingham Women's Hospital, for organising the GTA teaching sessions.

Contributors All authors meet the criteria for authorship, in detail: JC, TR and AJ designed the study; AJ conducted the study; collected and analysed the data. $\mathrm{NO}$ assisted with sensitivity analysis and bootstrapping. AJ wrote and revised the manuscript. TR supervised the study and assisted in analyses and review of the manuscript.

Funding Funding received from the University of Birmingham for payment of GTA teaching sessions to continue the trial.

Competing interests GTAs are currently employed by BWH where TJC is Director of Academy.

\section{Patient consent Not required.}

Ethics approval University of Birmingham and Birmingham Women's Hospital ethical approval granted.

Provenance and peer review Not commissioned; externally peer reviewed.

Data sharing statement Unpublished data for the randomised controlled trial, including demographics of the students, questionnaire information and student assessment scores, is available to authors: AJ and TJC. Detailed sensitivity analysis using Microsoft Excel is available to authors: AJ, TJC and TR.

Open access This is an open access article distributed in accordance with the Creative Commons Attribution Non Commercial (CC BY-NC 4.0) license, which permits others to distribute, remix, adapt, build upon this work non-commercially, and license their derivative works on different terms, provided the original work is 
properly cited and the use is non-commercial. See: http://creativecommons.org/ licenses/by-nc/4.0/

(c) Article author(s) (or their employer(s) unless otherwise stated in the text of the article) 2018. All rights reserved. No commercial use is permitted unless otherwise expressly granted.

\section{REFERENCES}

1. Broadmore J, Hutton JD, Langdana F. Medical students experience of vaginal examinations of anaesthetised women. BJOG 2009;116:731-3.

2. lyengar S, Raut N, Clark J. O330 Gynaecology Training Associates(GTAs): the future in the training of final year medical students? Int J Gynaecol Obstet 2012;119:S377.

3. Powell HS, Bridge J, Eskesen S, et al. Medical students' selfreported experiences performing pelvic, breast, and male genital examinations and the influence of student gender and physician supervision. Acad Med 2006;81:286-9.

4. General Medical Council (GMC), 2016. Outcomes for graduates pages 4 - 5 [Online]. http://www.gmc-uk.org/Outcomes_for graduates_Jul_15.pdf_61408029.pdf (Accessed 31 mar 2016).

5. Kretzschmar RM. Evolution of the Gynecology Teaching Associate: an education specialist. Am J Obstet Gynecol 1978;131:367-73.

6. Kretzschmar RM, Guthrie DS. Why not in every school? JAMWA 1983;39:43-5.

7. Smith PP, Choudhury S, Clark TJ. The effectiveness of gynaecological teaching associates in teaching pelvic examination: a systematic review and meta-analysis. Med Educ 2015:49:1197-206.

8. Pickard S, Baraitser P, Rymer J, et al. Comparative study. BMJ 2003;327:1389-92.
9. Pradhan A, Ebert G, Brug P, et al. Evaluating pelvic examination training: does faculty involvement make a difference? A randomized controlled trial. Teach Learn Med 2010;22:293-7.

10. Siwe K, Wijma B, Silén $C$, et al. Performing the first pelvic examination: female medical students' transition to examiners. Patient Educ Couns 2007;69:55-62.

11. Wånggren $\mathrm{K}$, Fianu Jonassen $\mathrm{A}$, Andersson $\mathrm{S}$, et al. Teaching pelvic examination technique using professional patients: a controlled study evaluating students' skills. Acta Obstet Gynecol Scand 2010;89:1298-303.

12. Black $B$, Marcoux BC. Feasibility of using standardized patients in a physical therapist education program: a pilot study. Journal of Physical Therapy Education 2002;16:49-56.

13. Aamodt CB, Virtue DW, Dobbie AE. Trained standardized patients can train their peers to provide well-rated, cost-effective physical exam skills training to first-year medical students. Fam Med 2006;38:326-9.

14. Drummond MF, Sculpher MJ, Claxton K, et al. Methods for the economic evaluation of health care programmes. Oxford: Oxford University Press, 2015.

15. Allen SS, Miller J, Ratner E, et al. The educational and financial impact of using patient educators to teach introductory physical exam skills. Med Teach 2011;33:911-8.

16. Hasle JL, Anderson DS, Szerlip HM. Analysis of the costs and benefits of using standardized patients to help teach physical diagnosis. Acad Med 1994:69:567-70.

17. Pugh CM, Salud LH. Association for Surgical Education. Fear of missing a lesion: use of simulated breast models to decrease student anxiety when learning clinical breast examinations. Am J Surg 2007; 193:766-70.

18. Claxton $\mathrm{K}$, Martin S, Soares M, et al. Methods for the estimation of the National Institute for Health and Care Excellence costeffectiveness threshold. Health Technol Assess 2015;19:1-504. 